\title{
ANALISIS PENERIMAAN PENGGUNA APLIKASI SIAKAD DESKTOP UNIVERSITAS BRAWIJAYA MENGGUNAKAN UTAUT
}

\author{
Yusi Tyroni Mursityo ${ }^{1}$, M. Chandra Saputra ${ }^{2}$, Admaja Dwi Herlambang ${ }^{3}$ \\ Sistem Informasi, Fakultas Ilmu Komputer, Universitas Brawijaya \\ Jl. Veteran No. 8 Malang \\ E-mail:yusi_tyro@ub.ac.id,andra@ub.ac.id,herlambang@ub.ac.id
}

\begin{abstract}
ABSTRAK
Layanan pendidikan dari perguruan tinggi saat ini telah banyak mengaplikasikan Sistem Informasi Akademik (SIAKAD). Pada penelitian tentang evaluasi heuristik pada Sistem Informasi Akademik Universitas Brawijaya didapatkan beberapa permasalahan yang terkait dengan pengguna antara lain permasalahan pada kemudahan pengguna dalam berinteraksi atau menggunakan aplikasi, SIAKAD Desktop yang tidak memberikan informasi pada user tentang kondisi suatu proses dalam jangka waktu atau saat tertentu. Di sisi lain, perguruan tinggi harus menjamin pemberian pelayanan yang terbaik. Oleh karena itu, perlu dilakukan evaluasi terhadap penerimaan pengguna SIAKAD Desktop untuk mengetahui faktor-faktor apa sajakah yang dapat mempengaruhi penggunaan SIAKAD Dekstop. UTAUT sebagai model teori akan dimanfaatkan untuk mengeksplorasi penerimaan dan penggunaan lingkungan teknologi, terutama pada pengguna SIAKAD pada bagian akademik Fakultas Ilmu Komputer Universitas Brawijaya. Data yang telah dikumpulkan kemudian akan dianalisis menggunakan metode Partial Least Square Sequence Equation Modelling (PLS SEM). Hasil analisis menunjukkan bahwa hanya kondisi fasilitas yang secara signifikan berpengaruh positif terhadap perilaku penggunaan SIAKAD Desktop. Model UTAUT hanya dapat menjelaskan 44,8\% varian faktor penggunaan SIAKAD Desktop yang termasuk dalam kategori moderat. Oleh karena itu perlu adanya pengembangan konstruk penyusun model penelitian agar prediksi akurasi varian dari model penelitian meningkat. Selain itu, diharapkan pada penelitian selanjutnya dapat mencakup target populasi yang lebih luas supaya data lebih reliabel.
\end{abstract}

Kata Kunci: utaut, penerimaan teknologi, siakad

\section{ABSTRACT}

Education services from tertiary institutions have applied a lot of the Academic Information System (SIAKAD). In the research on heuristic evaluation in the Academic Information System of Brawijaya University, there were several problems related to users, including problems in the ease of users to interact or use applications, SIAKAD Desktop which did not provide information to the user about the condition of a process within a certain time period or time. On the other hand, universities must guarantee the best service. Therefore, it is necessary to evaluate the acceptance of SIAKAD Desktop users to find out what factors can affect the use of Desktop SIAKAD. UTAUT as a theoretical model will be used to explore the acceptance and use of the technological environment, especially for SIAKAD users in the academic section of the Faculty of Computer Science, Universitas Brawijaya. The data that has been collected will then be analyzed using the Partial Least Square Sequence Equation Modeling (PLS SEM) method. The results of the analysis show that only the conditions of the facilities significantly influence the behavior of using SIAKAD Desktop. The UTAUT model can only explain $44.8 \%$ of the factor variants using SIAKAD Desktop which is included in the moderate category. Therefore, it is necessary to develop a research model construct construct so that the prediction of the variance accuracy of the research model increases. In addition, it is expected that further research can cover a wider population target so that data is more reliable.

Keywords: utaut, technology acceptance, siakad

\section{PENDAHULUAN}

\subsection{Latar Belakang}

Universitas Brawijaya merupakan Univesitas yang berlokasi di Kota Malang yang dalam pengolahan seluruh data dan kebutuhan informasi akademik baik untuk kebutuhan internal maupun eksternal sampai saat ini sudah menggunakan sistem informasi akademik. SIAKAD Desktop Universitas Brawijaya merupakan aplikasi Sistem Informasi Akademik berbasis Desktop yang digunakan oleh operator akademik. SIAKAD Desktop Universitas
Brawijaya memiliki fungsi spesifik, antara lain: (1) antarmuka yang didesain khusus bagi operator akademik; (2) memuat transaksi akademik mahasiswa (KRS, KHS, Transkrip, dan lain-lain); (3) memuat data perkuliahan (jadwal kuliah, absensi mahasiswa, nama matakuliah, dosen pengampu, dan lain-lain); dan (4) memberikan dukungan terhadap perubahan kurikulum (penggabungan kuliah, perubahan sks, perubahan nama, dan lain-lain).

Unified Theory of Acceptance and Use of Technology (UTAUT) yang digagas oleh 
Venkatesh, et al. (2003) merupakan model yang telah dirancang untuk mengeksplorasi penerimaan dan penggunaan lingkungan teknologi. UTAUT adalah model penerimaan teknologi yang merupakan pengembangan dari delapan model pendahulunya yaitu TRA, TAM, MM, TPB, C-TAM-TPB, MPCU, IDT, dan SCT. Dengan model UTAUT peneliti dapat mengetahui dan menjelaskan faktor yang mempengaruhi niat perilaku menggunakan teknologi dan memprediksi kemungkinan penggunaannya.

Pengaruh Ilmu Pengetahuan dan Teknologi (IPTEK) menjadi sebuah hal yang tidak bisa dihidari lagi saat ini terlebih dalam dunia pendidikan, segala sesuatu sudah hampir menggunakan teknologi. Jenis-jenis pekerjaan yang sebelumnya menuntut kemampuan fisik cukup besar, kini relatif sudah bisa digantikan oleh perangkat mesin-mesin dan teknologi. Kondisi pemanfaatan teknologi dalam dunia pendidikan khususnya di Univeristas Brawijaya yang telah menerapkan sejak tahun 2000 dirasa perlu mengetahui sudut pandang pengguna terhadap layanan yang sudah disediakan oleh pihak Univeristas Brawijaya untuk kebutuhan operasional akademik yaitu SIAKAD. Pada teorinya UTAUT dapat menjelaskan faktor-faktor yang mendorong penggunaan sebuah teknologi dan pada penelitian ini berfokus pada SIAKAD Desktop.

Venkatesh et al. (2003) merumuskan sebuah model yang menyatukan perspektif teori umum dari literatur pendahulunya yaitu TRA (Theory of Reasoned Action), TAM (Technology Acceptance Model), MM (Motivational Model), TPB (Theory of Planned Behavior), C-TAM-TPB (Combined TAMTPB), MPCU (Model of PC Utilzation), IDT (Innovation Diffusion Theory), dan SCT (Social Cognitive Theory) serta menggabungkan empat moderator untuk meneliti pengaruh dinamis seperti konteks organisasi, pengalaman pengguna, dan karakteristik demografi. Dari hasil penelitian Unified Theory of Acceptance and Use of Technology (UTAUT) terbukti mengungguli kedelapan model tersebut karena dapat menjelaskan 70 persen varian dalam niat perilaku (intention). Sehingga hal tersebut dapat menjelaskan penerimaan individu dan keputusan penggunaan dalam organisasi.

Dalam lingkungan disiplin teknologi informasi atau komputasi, penggunaan terminologi studi kasus atau studi pada menunjukkan adanya skenario dimana penelitian yang dilakukan akan menggunakan teknik pemodelan, metode atau program. Skenario yang digunakan terkadang terkesan dibuat-buat dan biasanya lebih sederhana daripada yang terjadi di dalam kehidupan nyata. Penelitian ini menggunakan metode survei karena tidak melibatkan melibatkan pengaturan atau manipulasi akan variabel independen (Recker, 2013) dan merupakan sebuah cara untuk mengumpulkan informasi mengenai karakteristik, aksi, persepsi, sikap atau opini dari sekumpulan kelompok besar dari unit yang dilakukan observasi (seperti individu, kelompok atau organisasi) atau populasi.

Model UTAUT terdiri dari empat variabel yang mempunyai peran signifikan sebagai determinan langsung penerimaan teknologi dan perilaku penggunaan. Keempat kosntruk tersebut adalah ekspektasi kinerja (performance expectancy), ekspektasi usaha (effort expectancy), pengaruh sosial (social influence), dan kondisi yang memfasilitasi (facilitating condition). Menurut Recker untuk penelitian kuantitatif salah satu metode yang populer adalah dengan melakukan survei, dimana penelitian berbasis survei dalam penelitian eksplanatoris digunakan untuk menanyakan mengenai hubungan antar variabel dari teori (Ajanović \& Ivanović, 2014). Sehingga jenis penelitian eksplanatoris dan metode survey dapat membantu penelitian ini dalam melakukan pengujian teori dan investigasi model UTAUT.

Tujuan penelitian ini adalah untuk menganalisis penerimaan pengguna SIAKAD Desktop Universitas Brawijaya menggunakan UTAUT, menguji variabel penelitian model UTAUT untuk penerimaan pengguna SIAKAD Desktop sehingga dapat memberikan rekomendasi perbaikan dari aspek penerimaan pengguna SIAKAD Desktop Universitas Brawijaya. Urgensi penelitian ini adalah perlunya menganalisis SIAKAD Desktop Universitas Brawijaya dari sisi penerimaan pengguna, sehingga kebutuhan perbaikan sistem dapat terindentifikasi dari sisi pengguna. Perbaikan tersebut dapat meningkatkan produktivitas pekerjaan serta dapat meningkatkan penerimaan sistem yang berkaitan dengan pengguna SIAKAD Desktop Universitas Brawijaya.

\subsection{Pengumpulan Data}

Data yang digunakan dalam penelitian ini adalah data primer berupa survei kuisioner terstruktur. Menurut Delbridge dan Kirkpatrick (Saunders, et al., 2009) mengkategorikan jenis data yang dihasilkan oleh partisipan observasi adalah primer, sekunder, dan experiental. Data primer merujuk kepada informasi yang diperoleh sendiri oleh peneliti pada variabel yang diteliti sesuai dengan tujuan penelitian. Sumber data primer dapat berupa individu, grup fokus, panel responden yang telah diatur oleh peneliti dan dari siapakah opini yang dapat dicari pada isu-isu tertentu dari waktu ke waktu, atau beberapa sumber yang dianggap sepele seperti tempat sampah (Sekaran, 2003).

Penelitian ini akan menggunakan studi satu tahap (one-shot study) atau studi lintas sekat (crosssectional study) dimana data akan dikumpulkan dalam satu tahapan waktu sekali saja, baik dalam periode beberapa hari atau minggu atau bulan untuk menjawab tujuan penelitian (Sekaran, 2003). Dalam penelitian ini akan digunakan pengambilan sampel jenuh dari seluruh populasi bagian akademik FILKOM. 
Structural Equation Modeling (SEM) merupakan salah satu analisis multivariat yang dapat menganalisis hubungan antarvariabel secara lebih kompleks (Sarjono \& Julianita, 2015). Teknik ini dapat menguji hubungan di antara variabel laten dengan variabel manifes (persamaan hubungan). SEM menggabungkan dua metode statistik yaitu analisis faktor yang dikembangkan dalam psikologi/ psikometri atau sosiologi dan model persamaan simultan yang dikembangkan dalam ekonometri (Yamin \& Kurniawan, 2009). Partial Least Square (PLS) adalah analisis persamaan struktural (SEM) berbasis varian yang secara simultan dapat melakukan pengujian model pengukuran sekaligus model struktural. Perbedaan mendasar antara SEM yang berbasis varian dengan LISREL atau AMOS yang berbasis kovarian adalah tujuan penggunaannya. SEM berbasis kovarian bertujuan untuk mengestimasi model untuk pengujian atau konfirmasi teori, sedangkan SEM varian bertujuan untuk memprediksi model untuk pengembangan teori. Karena itu, PLS merupakan alat prediksi kausalitas yang digunakan untuk pengembangan teori (Abdillah \& Hartono, 2015) dan sesuai untuk diaplikasikan pada penelitian ini.

\section{PEMBAHASAN}

Analisa kebutuhan menggunakan variabelvariabel yang terlibat dalam penelitian ini dirujuk dari Venkatesh yang menjelaskan tentang variabel dalam UTAUT menggunakan variabel sebagai berikut:

a. Performance Expectancy (PE), sebagai variabel harapan pengguna terhadap kinerja sistem.

b. Effort Expectancy (EE), sebagai variabel harapan pengguna terhadap kebutuhan untuk menjalankan sistem.

c. Social Influence (SI), sebagai variabel pengaruh dari lingkungan sosial sekitar pengguna.

d. Facilitating Conditions (FC), sebagai variabel kondisi yang memfasilitasi pengguna untuk menjalankan sistem.

e. Behavioral Intention (BI), variabel niatan dari perilaku pengguna untuk menggunakan sistem.

f. Use Behavior (UB), variabel perilaku pengguna dalam menjalankan sistem.

Setelah hasil analisa kebutuhan didapat, penelitian fokus pada analisa penerimaan SIAKAD Desktop Universitas Brawijaya yang menghasilkan hasil pengukuran pengguna yang mempengaruhi penerimaan SIAKAD Desktop yang ada pada Fakultas Ilmu Komputer Universitas Brawijaya. Metode UTAUT memungkinkan untuk mengetahui penerimaan menggunakan kuesioner yang diisikan oleh petugas SIAKAD Desktop Fakultas Ilmu Komputer Universitas Brawijaya. Data yang telah terkumpul dari pengguna selanjutnya akan diproses dan dianalisis menggunakan metode SEM PLS.

Hasil pengukuran akan diuji dengan hipotesa yang akan digunakan dalam penelitian ini. Berikut adalah hipotesis UTAUT yang akan diujikan dengan hasil kuesioner.

H1. Performance Expectancy mempengaruhi Behavioral Intention pada SIAKAD Desktop Fakultas Ilmu Komputer Universitas Brawijaya.

H2. Effort Expectancy mempengaruhi Behavioral Intention pada SIAKAD Desktop Fakultas Ilmu Komputer Universitas Brawijaya.

H3. Social Influence mempengaruhi Behavioral Intention pada SIAKAD Desktop Fakultas Ilmu Komputer Universitas Brawijaya.

H4. Facilitating Condition mempengaruhi Use pada SIAKAD Desktop Fakultas Ilmu Komputer Universitas Brawijaya.

H5. Behavioral Intention mempengaruhi Use pada SIAKAD Desktop Fakultas Ilmu Komputer Universitas Brawijaya.

Responden dalam penelitian ini adalah pegawai akademik yang telah berpengalaman menggunakan SIAKAD Desktop dengan jumlah total 9 pegawai. Pengumpulan data dilakukan pada bulan Juli 2017. Berdasarkan data dalam Tabel 4.1 terdapat 8 responden laki-laki $(88,9 \%)$ dan 1 responden perempuan $(11,1 \%)$. Sebagian besar responden berusia 26-40 tahun (100\%) yang telah bekerja selama lebih dari tiga tahun $(66,7 \%)$ dan telah berpengalaman menggunakan SIAKAD Desktop selama kurang dari satu tahun $(44,4 \%)$ dan lebih dari tiga tahun $(44,4 \%)$.

Tabel 1. Hasil Uji Reliabilitas

\begin{tabular}{|c|c|c|}
\hline $\begin{array}{c}\text { Variabel } \\
\text { laten }\end{array}$ & $\begin{array}{c}\text { Composite } \\
\text { Reliabilities }\end{array}$ & $\begin{array}{c}\text { Cronbach's } \\
\text { Alpha }\end{array}$ \\
\hline BI & 0,9331 & 0,8571 \\
\hline EE & 0,901 & 0,8416 \\
\hline FC & 0,8865 & 0,8077 \\
\hline PE & 0,9445 & 0,883 \\
\hline SI & 0,0212 & $-1,3073$ \\
\hline UB & 0,8283 & 0,6951 \\
\hline
\end{tabular}

Berdasarkan data dalam Tabel 1 variabel BI, EE, FC, dan PE memiliki rata-rata nilai composite reliabilities 0,9 dan cronbach's alpha 0,8 menunjukkan nilai reliabilitas yang baik. Variabel UB memiliki nilai cronbach's alpha $<0,7$, namun masih termasuk ke dalam reliabilitas yang baik karena memiliki nilai composite reliabilities senilai 0,8 . Variabel SI tidak memenuhi kriteria nilai reliabilitas yang baik karena nilai composite reliabilities dan cronbach's alpha kurang dari 0,7. Wijanto (2009) menyarankan bahwa respesifikasi model penelirian sebaiknya lebih diarahkan menggunakan theory-driven. Oleh karena itu, variabel SI tetap dipertahankan dalam penelitian karena jika dihapus dalam model penelitian, maka dapat mengubah validitas konten dalam model penelitian. Hal ini juga didukung dari jawaban responden yang menyatakan bahwa terdapat 
pengaruh sosial di lingkungan kerja yang mendorong penggunaan SIAKAD.

Kriteria fornell-larcker dapat dilihat dalam Tabel 2. Berdasarkan data tersebut variabel BI memiliki nilai $\sqrt{ }$ AVE senilai 0,93 yang lebih besar dibandingkan dengan nilai korelasi variabel $\mathrm{BI}$ terhadap EE $(0,1)$, FC $(0,43)$, PE $(0,53)$, SI $(0,68)$, dan UB $(0,3)$. Variabel EE, SI, FC, BI, dan UB juga memiliki nilai $\sqrt{ }$ AVE yang lebih besar dibandingkan dengan nilai korelasi variabel laten lainnya. Sehingga, seluruh variabel dalam model penelitian memenuhi kriteria fornell-larcker.

Tabel 2. Kriteria fornell-larcker

\begin{tabular}{|c|c|c|c|c|c|c|}
\hline & BI & EE & FC & PE & SI & UB \\
\hline BI & $\mathbf{0 , 9 3 5}$ & 0 & 0 & 0 & 0 & 0 \\
\hline EE & $-0,114$ & $\mathbf{0 , 8 6 8}$ & 0 & 0 & 0 & 0 \\
\hline FC & 0,438 & $-0,109$ & $\mathbf{0 , 8 5 1}$ & 0 & 0 & 0 \\
\hline PE & 0,532 & $-0,062$ & 0,374 & $\mathbf{0 , 9 4 6}$ & 0 & 0 \\
\hline SI & 0,680 & 0,326 & 0,548 & 0,554 & $\mathbf{0 , 8 3 3}$ & 0 \\
\hline UB & 0,300 & $-0,299$ & 0,669 & $-0,109$ & 0,080 & $\mathbf{0 , 7 9 0}$ \\
\hline
\end{tabular}

Nilai cross loading masing-masing indikator dapat dilihat dalam Tabel 3. Berdasarkan data tersebut, indikator BI1 memiliki nilai outer loading 0,88 yang jumlahnya lebih besar dibandingkan nilai outer loading terhadap variabel lainnya seperti EE $(0,0), \mathrm{FC}(0,37), \mathrm{PE}(0,51)$, SI $(0,75)$, dan UB $(0,23)$. Berdasarkan data dalam tabel, seluruh indikator lainnya juga memiliki nilai outer loading yang lebih tinggi terhadap variabel latennya masing-masing dibandtingkan terhadap variabel laten lainnya. Sehingga, dapat disimpulkan bahwa seluruh variabel laten dan indikatornya memenuhi validitas diskriminan.

Tabel 3. Cross loading

\begin{tabular}{|l|r|l|l|l|l|l|}
\hline & BI & \multicolumn{1}{|c|}{ EE } & FC & PE & SI & UB \\
\hline BI1 & 0,944 & 0,000 & 0,370 & 0,516 & 0,755 & 0,237 \\
\hline BI2 & 0,926 & $-0,229$ & 0,455 & 0,477 & 0,500 & 0,331 \\
\hline EE1 & $-0,062$ & 0,753 & 0,129 & $-0,297$ & 0,111 & 0,331 \\
\hline EE3 & $-0,125$ & 0,915 & $-0,429$ & $-0,078$ & 0,245 & $-0,598$ \\
\hline EE4 & $-0,094$ & 0,925 & 0,196 & 0,136 & 0,462 & $-0,214$ \\
\hline FC1 & 0,062 & $-0,148$ & 0,902 & 0,297 & 0,245 & 0,614 \\
\hline FC2 & 0,659 & $-0,251$ & 0,905 & 0,516 & 0,496 & 0,630 \\
\hline FC3 & 0,410 & 0,206 & 0,735 & 0,078 & 0,748 & 0,443 \\
\hline PE1 & 0,534 & 0,009 & 0,323 & 0,953 & 0,503 & $-0,206$ \\
\hline PE2 & 0,468 & $-0,136$ & 0,388 & 0,939 & 0,548 & 0,014 \\
\hline SI2 & 0,646 & 0,121 & 0,407 & 0,477 & 0,888 & $-0,058$ \\
\hline SI4 & $-0,468$ & $-0,485$ & $-0,533$ & $-0,449$ & $-0,773$ & $-0,239$ \\
\hline UB1 & 0,094 & $-0,468$ & 0,584 & $-0,136$ & $-0,193$ & 0,929 \\
\hline UB2 & 0,428 & $-0,102$ & 0,615 & $-0,228$ & 0,393 & 0,809 \\
\hline UB3 & 0,158 & $-0,102$ & 0,325 & 0,262 & $-0,098$ & 0,596 \\
\hline
\end{tabular}

Variabel PE, EE, SI, FC, BI, dan UB beserta masing-masing indikatornya memenuhi kriteria validitas konvergen. Selain itu, variabel laten dan masing-masing indikatornya juga memenuhi kriteria fornell-larcker dan cross loading yang termasuk dalam validitas diskriminan. Sebelum melakukan pengujian struktural, setiap variabel laten dalam hipotesis harus diuji terlebih dahulu kolinearitasnya. Dalam data tersebut, nilai VIF paling tinggi adalah 2,4 yang dimiliki oleh hubungan antara variabel SI dengan BI. Sehingga dapat disimpulkan bahwa seluruh hubungan dalam model penelitian memenuhi kriteria VIF $<5$. Oleh karena itu, indikasi adanya kolinearitas dalam setiap hubungan antarvariabel laten kecil dan perhitungan estimasi akurat.

Dalam pengujian model struktural hubungan antara variabel laten signifikan jika nilai t-value > 1,96 dan nilai p-value $<0,05$. Hipotesis $\mathrm{H} 2$ memiliki hubungan yang signifikan karena memiliki t-value dan p-value senilai 4,6 dan 0,001. Berdasarkan hasil pengujian struktural terdapat tiga hipotesis yang memiliki hubungan yang signifikan yaitu hipotesis $\mathrm{H} 2$, H3, dan H4. Hipotesis H2 memiliki nilai path coefficient negatif dengan nilai $-0,348$. Hipotesis H1 dan H5 memiliki hubungan yang tidak signifikan karena memiliki nilai t-value $<1,96$ dan $\mathrm{p}$-value $<$ 0,05 .

Hubungan antarvariabel yang memiliki nilai tvalue $>1,96$ dan $\mathrm{p}$-value $<0,05$ dinyatakan memiliki hubungan yang signifikan dan menunjukkan bahwa hipotesis diterima. Jika tidak memenuhi kriteria maka hubungan antarvariabel tidak signifikan Terdapat tiga hipotesis yang diterima dan dua hipotesis yang ditolak. Hipotesis yang diterima adalah hipotesis H2, H3, dan H4. Sedangkan hipotesis yang ditolak antara lain hipotesis $\mathrm{H} 1$ dan H5. Untuk lebih jelasnya, hasil pengujian hipotesis dapat dilihat dalam Tabel 4. berikut ini.

Tabel 4. Hasil pengujian hipotesis

\begin{tabular}{|c|c|c|}
\hline $\begin{array}{c}\text { Hipo- } \\
\text { tesis }\end{array}$ & Keterangan & $\begin{array}{l}\text { Kepu- } \\
\text { tusan }\end{array}$ \\
\hline H1. & $\begin{array}{l}\text { Performance expectancy } \\
\text { (PE) berpengaruh positif } \\
\text { terhadap behavioral } \\
\text { intention (BI). }\end{array}$ & Ditolak \\
\hline $\mathrm{H} 2$. & $\begin{array}{l}\text { Effort expectancy (EE) } \\
\text { berpengaruh positif terhadap } \\
\text { behavioral intention }(\mathrm{BI}) .\end{array}$ & Ditolak \\
\hline H3. & $\begin{array}{l}\text { Social influence (SI) } \\
\text { berpengaruh positif terhadap } \\
\text { niat behavioral intention } \\
(\mathrm{BI}) \text {. }\end{array}$ & $\begin{array}{l}\text { Diteri } \\
\text { ma }\end{array}$ \\
\hline H4. & $\begin{array}{l}\text { Facilitating condition (FC) } \\
\text { berpengaruh positif terhadap } \\
\text { use behavior (UB). }\end{array}$ & $\begin{array}{l}\text { Diteri } \\
\text { ma }\end{array}$ \\
\hline H5. & $\begin{array}{l}\text { Behavioral intention (BI) } \\
\text { berpengaruh positif terhadap } \\
\text { use behavior (UB). }\end{array}$ & Ditolak \\
\hline
\end{tabular}

Selanjutnya pembahasan dari 5 hipotesis dijabarkan lebih lanjut :

1. Pembahasan hipotesis 1

Hasil pengujian hipotesis 1 menyatakan bahwa performance expectancy (PE) tidak berpengaruh 
signifikan terhadap behavioral intention (BI). Meskipun terdapat peningkatan kinerja, namun hal tersebut tidak mempengaruhi niat pengguna untuk menggunakan SIAKAD Desktop. Hal ini dikarenakan SIAKAD Desktop diperlukan untuk menyelesaikan seluruh kegiatan dan administrasi akademik. Jika tidak ada SIAKAD Desktop, maka pegawai akademik tidak dapat melakukan pekerjaannya. Sehingga pengguna akan terus menggunakan SIAKAD Desktop untuk menyelesaikan pekerjaannya. Nienhuis (2014) juga menyatakan bahwa peningkatan kinerja tidak berpengaruh terhadap niat perilaku. Hal ini dikarenakan tidak adanya dampak langsung berupa merit bonus atau promosi dengan menggunakan sistem CRM.

2. Pembahasan hipotesis $\mathrm{H} 2$

Hasil pengujian hipotesis $\mathrm{H} 2$ menyatakan bahwa effort expectancy (EE) berpengaruh negatif terhadap behavioral intention (BI), sehingga hipotesis $\mathrm{H} 2$ ditolak. Semakin rumit transaksi akademik yang dapat dilakukan oleh SIAKAD Desktop, maka akan meningkatkan keinginan untuk menggunakan SIAKAD Desktop. Hal ini disebabkan SIAKAD Desktop mendukung fitur-fitur yang kompleks untuk melakukan proses transaksi akademik, sehingga pemakaiannya menjadi lebih rumit atau kompleks. Meskipun demikian, sebagian besar responden menyatakan bahwa mereka telah terbiasa menggunakan SIAKAD Desktop, sehingga membuat mereka merasa tidak kesulitan untuk menggunakannya.

3. Pembahasan hipotesis $\mathrm{H} 3$

Hasil pengujian hipotesis H3 menyatakan bahwa social influence (SI) berpengaruh positif terhadap behavioral ntention (BI), sehingga hipotesis H3 diterima. Adanya pengaruh lingkungan kerja membuat semua pegawai akademik berniat menggunakan SIAKAD Desktop untuk menyelesaikan pekerjaannya. Pengaruh tersebut antara lain adalah adanya kebijakan dari Fakultas yang mengharuskan pegawai akademik untuk menggunakan SIAKAD Desktop. Sehingga pelayanan administrasi akademik mahasiswa seharihari seluruhnya dilakukan menggunakan SIAKAD Desktop.

4. Pembahasan hipotesis $\mathrm{H} 4$

Hasil pengujian hipotesis $\mathrm{H} 4$ menyatakan bahwa facilitating condition (FC) berpengaruh positif terhadap use behavior (UB), sehingga hipotesis H4 diterima. Tersedianya fasilitas dan pengetahuan yang diperlukan untuk menggunakan SIAKAD Desktop membuat pegawai akademik memutuskan untuk untuk menggunakannya. Selain itu, mudahnya akses dan bantuan ketika terjadi permsalahan membuat pegawai akademik merasa nyaman ketika menggunakan SIAKAD Desktop.

\section{Pembahasan hipotesis H5}

Hasil pengujian hipotesis H5 menyatakan bahwa behavioral intention (BI) tidak berpengaruh signifikan terhadap use behavior (UB), sehingga hipotesis H5 ditolak. Niat menggunakan tidak berpengaruh terhadap keputusan pengguna untuk menggunakan SIAKAD Desktop. Meskipun tidak ada niat, pegawai akademik tetap dituntut untuk menggunakan SIAKAD Desktop. Hasil ini didukung oleh Nienhuis (2014) yang menyatakan bahwa niat perilaku tidak berdampak signifikan terhadap perilaku penggunaan.

Dan untuk pembahasan mengenai R-square sebagaimana berikut. BI memiliki nilai R-Square sebesar 59,4\%. BI dipengaruhi oleh variabel PE, EE, dan SI. Pengaruh ketiga variabel tersebut tergolong moderat karena hanya dapat menjelaskan setengah dari keseluruhan faktor yang memengaruhi memengaruhi BI. Secara statistik hanya variabel $\mathrm{EE}$ dan SI yang terbukti berpengaruh signifikan terhadap BI. Selain itu, nilai path coefficient SI $(0,73)$ lebih besar dari pada EE $(0,34)$, sehingga dapat disimpulkan bahwa pengaruh lingkungan sosial lebih berpengaruh dominan dari pada kemudahan usaha. Kebijakan Fakultas yang mengharuskan pegawai akademik untuk menggunakan SIAKAD Desktop menyelesaikan pekerjaan merupakan faktor utama yang mendorong niat pegawai menggunakan SIAKAD Dekstop.

UB memiliki nilai R-Square sebesar $44,8 \%$. Hal ini berarti bahwa penggunaan SIAKAD Desktop dipengaruhi oleh BI, dan FC. Pengaruh kedua variabel laten tersebut tergolong moderat karena dapat menjelaskan sekitar setengah dari faktor-faktor yang memengaruhi UB secara keseluruhan. Secara statistik hanya variabel FC yang terbukti berpengaruh signifikan terhadap USE. SIAKAD Desktop hanya dapat diakses dalam komputer di lingkungan kerja akademik FILKOM.

\section{KESIMPULAN}

Berdasarkan hasil analisis penerimaan penerimaan aplikasi SIAKAD Desktop dapat diambil kesimpulan sebagai berikut:

Kesesuaian model UTAUT terhadap penerimaan pengguna SIAKAD Desktop termasuk kategori moderat karena model UTAUT hanya mampu menjelaskan $44,8 \%$ varian pada pembentukan perilaku penggunaan SIAKAD Desktop. Sementara $65,2 \%$ varian pembentuk perilaku penggunaan SIAKAD Desktop dijelaskan oleh variabel lain di luar model penelitian.

Berdasarkan hasil penelitian, hubungan pengaruh variabel penelitian didapatkan hasil sebagai berikut: Ekspektasi terhadap kenaikan kinerja tidak mempengaruhi niat perilaku penggunaan SIAKAD Desktop. Kemudahan usaha dan pengaruh sosial berpengaruh signifikan terhadap niat perilaku. Namun, secara tidak langsung keduanya tidak berpengaruh signifikan terhadap perilaku penggunaan SIAKAD Desktop. Hal ini dikarenakan niat perilaku yang tidak berpengaruh signifikan terhadap perilaku penggunaan SIAKAD Desktop. 
Kondisi fasilitas merupakan satu-satunya variabel yang berpengaruh positif terhadap perilaku penggunaan SIAKAD Desktop. Oleh karena itu, untuk meningkatkan penerimaan pengguna SIAKAD Desktop, maka pihak Fakultas Ilmu Komputer perlu menyediakan sarana dan bantuan yang baik supaya kegiatan akademik dapat berjalan dengan baik.

Penerimaan aplikasi SIAKAD Desktop dengan menggunakan model UTAUT hanya mampu menjelaskan $44,8 \%$ dari seluruh varian faktor yang memengaruhi penggunaan aplikasi SIAKAD Desktop. Pada penelitian selanjutnya dapat ditambahkan variabel laten (konstruk) lain yang secara langsung memengaruhi perilaku penggunaan untuk meningkatkan persentase tersebut. Oleh karena itu perlu adanya pengembangan konstruk penyusun model penelitian agar prediksi akurasi varian dari model penelitian meningkat.

\section{PUSTAKA}

Abdillah, W. \& Hartono, J., 2015. Partial Least Square (PLS) Alternatif Structural Equation Modeling (SEM) dalam Penelitian Bisnis. Yogyakarta: Andi Offset.

Ajanović, A. \& Ivanović, K., 2014. Cognitive absorption and the behavioral intention to use business intelligence: Determinants and influence of cognitive absorption, Lund, Sweden: Lund University Thesis.

Hair., J. F., Hult, G. M., Ringle, C. M. \& Sarstedt, M., 2013. A Primer on Partial Least Squares Structural Equation Modeling (PLS-SEM). United States of America: SAGE Publications, Inc.

Henseler, J., Ringle, C. M. \& Sinkovics, R. R., 2009. THE USE OF PARTIAL LEAST SQUARES PATH MODELING IN INTERNATIONAL MARKETING. Advances in International Marketing, Volume 20, pp. 277-319.

Nienhuis, J., 2014. Using change management to improve CRM user acceptance, Enschede: University of Twente.

Recker, J., 2013. Scientific Research in Information Systems: A Beginner's Guide. Berlin: Springer.

Sarjono, H. \& Julianita, W., 2015. Structural Equation Modeling Sebuah Pengantar, Aplikasi untuk Penelitian Bisnis. Jakarta: Salemba Empat.

Saunders, M., Lewis, P. \& Thornhill, A., 2009. Research Methods for Business Student 5th edition. Edinburgh Gate: Pearson Education Limited.

Sekaran, U., 2003. Research Methods for Business: A Skill-Building Approach 4th edition. New York: John Wiley \& Sons, Inc.

Sumak, B. \& Sorgo, A., 2016. The acceptance and use of interactive whiteboards among teachers: Differences in UTAUT determinants between pre- and post-adopters. Computers in Human Behavior, Volume 64, pp. 602-620.
Venkatesh, V., Morris, M. G., Davis, G. B. \& Davis, F. D., 2003. User Acceptance of Information Technology: Toward a Unified View. MIS Quarterly, 23(3), pp. 425-478. 